\title{
Value of 3D-DSA in the detection of
} intracranial aneurysms: the comparison of $3 \mathrm{D}$
technique and digital subtraction angiography

\section{Vrijednost 3D-DSA u detekciji intrakranijalnih aneurizama: usporedba 3D tehnike i digitalne suptrakcijske angiografije}

\section{Darjan Franjicí ${ }^{*}$, Josip Mašković ${ }^{2}$}

${ }^{1}$ Klinika za onkologiju, Sveučilišna klinička bolnica Mostar, Mostar, Bosna i Hercegovina ${ }^{2}$ Odjel za radiologiju, Sveučilišna klinička bolnica Mostar, Mostar, Bosna i Hercegovina

\section{*Corresponding author:}

Darjan Franjić, mag. rad. techn.

Klinika za onkologiju, Sveučilišna klinička bolnica Mostar

Ulica kralja Tvrtka bb, 88000 Mostar, Bosna i Hercegovina

E-mail: darjanfranjic@gmail.com
Abstract. Aim: To determine the value of three-dimensional (3D) digital subtraction angiography (DSA) in the detection of intracranial aneurysms and to compare 3D technique with DSA. Materials and Methods: A retrospective analysis of 50 patients with 60 intracranial aneurysms who underwent both conventional DSA and 3D-DSA for the evaluation of intracranial aneurysms was conducted. The presence of aneurysms, detection of aneurysmal neck, size, location, presence of additional and small aneurysms analyzed from the two protocols were compared. Results: Three-dimensional technique detected 54 aneurysms while conventional DSA detected 38 aneurysms. There was no correlation between aneurysm detection and aneurysm neck detection in the two technologies observed, but there was a difference in detection performance depending on the technology used. Threedimensional technique detected 52 aneurysm necks while conventional DSA detected 24 aneurysm necks. There was a statistically significant and positive relationship between the detected size of the aneurysm using 3D technique and DSA technology. Three-dimensional technique detected 24 additional aneurysms while conventional DSA detected only six additional aneurysms. Conclusions: Three-dimensional technique are more successful in the detection of aneurysms, their necks and small aneurysms in comparison to digital subtraction angiography, but difference is not statistically significant. The size of the aneurysm statistically significant affects the aneurysm neck detection by conventional DSA.

Key words: angiography; cerebral aneurysm; digital subtraction angiography; intracranial aneurysm

Sažetak. Cilj: Utvrditi vrijednost trodimenzionalne (3D) digitalne suptrakcijske angiografije (DSA) u detekciji intrakranijalnih aneurizama te usporediti 3D tehniku i DSA. Materijali i metode: Provedena je retrospektivna analiza 60 aneurizama koje su otkrivene u 50 pacijenata koji su podvrgnuti pregledu konvencionalnom DSA i 3D-DSA metodom u svrhu evaluacije intrakranijalnih aneurizama. Prisutnost aneurizme, detekcija vrata, veličine i lokacije aneurizme te prisutnost dodatnih i malih aneurizama parametri su koji su uspoređivani dvama protokolima. Rezultati: Metodom 3D tehnike detektirane su 54 aneurizme, dok je DSA metodom detektirano 38 aneurizama. $U$ detekciji aneurizme i njezinog vrata između dviju metoda nije zabilježena statistički značajna razlika, ali je zabilježena razlika u uspješnosti u detekciji ovisno o korištenoj metodi. Statistički značajna pozitivna povezanost zabilježena je u određivanju veličine aneurizme između konvencionalne DSA i 3D tehnike. Pomoću 3D tehnike detektirane su 24 dodatne aneurizme, dok je konvencionalnom DSA metodom detektirano samo šest dodatnih aneurizama. Zaključci: Trodimenzionalna tehnika uspješnija je u detekciji intrakranijalnih aneurizama, njihovih vratova i malih aneurizama u usporedbi $s$ digitalnom suptrakcijskom angiografijom, ali razlika nije statistički značajna. Veličina aneurizme statistički značajno utječe na detekciju vrata aneurizme konvencionalnom DSA metodom.

Ključne riječi: angiografija; cerebralna aneurizma; digitalna suptrakcijska angiografija; intrakranijalna aneurizma 


\section{INTRODUCTION}

An intracranial aneurysms are weak dilations at major bifurcating brain arteries and have a prevalence of $3 \%$ in the middle-aged population ${ }^{1}$. Timely detection and treatment of intracranial aneurysms are crucial in prevention of rupture of intracranial aneurysms and subarachnoid hemorrhage $^{2}$. Detection and precise morphologic evaluation of the aneurysm neck is important for intracranial aneurysm management and for the choice of treatment method ${ }^{3-5}$. Digital subtraction angiography (DSA) is the gold standard method in the diagnosis of preoperative intracranial aneurysms because of excellent depiction of cerebrovascular anatomy structures and superior spatial resolution in comparison with three-dimensional (3D)-computed tomography (CT) and magnetic resonance angiography $(M R A)^{6,7}$. In some cases, it is difficult to determine the relationship between multiple overlapping vessels and intracranial aneurysm neck from two-dimensional (2D) images. Three-dimensional DSA allows interventional radiologists to obtain an aneurysm morphology from multiple angles ${ }^{8}$. Most hospitals in developing country can only afford 2D angiography devices for the expensive cost of 3D devices ${ }^{9}$.

Considering the added advantage of 3D-DSA over conventional DSA, the aim of this study is to compare conventional DSA with 3D technique in the detection of intracranial aneurysms and their necks. The main aim of this study is to compare conventional DSA and 3D technique in the detection of aneurysm neck, small aneurysms and additional aneurysms.

\section{MATERIALS AND METHODS}

\section{Patients}

A retrospective analysis of 60 patients with subarachnoid hemorrhage who underwent both DSA and $3 D$ rotational DSA for evaluation of intracranial aneurysms was conducted at Department of Radiology in University Clinical Hospital Mostar between January and March 2019. The patient population consisted of 32 females and 18 males (age range $28-81$; mean=53.67). Exclusion criteria represented an excessive artifacts distortion in 2D DSA or 3D rotation DSA images. Of the 60 patients, four were excluded due to excessive artifacts distortion of 3D rotation DSA images. Six patients were excluded due to lack of examination by 3D rotational DSA. The study was approved by our local institutional review board.

\section{Angiography techniques}

DSA was performed by using a single plane angiography unit that has rotational capabilities (General electric (GE) Medical Systems, Inova

Three-dimensional reconstructions are more successful in the detection of aneurysms, their necks and small aneurysms. If the conventional DSA detects a larger size of the aneurysm, a larger aneurysm will also be detected using 3D technology. The size of the aneurysm affects the aneurysm neck detection by conventional DSA.

4100 IQ Cath Lab, United States). This protocol included standard anteroposterior (AP), lateral and oblique views with a Performix 160A X-Ray Tube, Innova $100 \mathrm{~kW}$ Generator, Omega V Angiographic Table, and Innova DL Digital Imaging Subsystem. As usual, $7-10 \mathrm{~mL}$ of nonionic contrast (lopromide [Ultravist], $300 \mathrm{mgl} / \mathrm{Ml}$; GE Healthcare) was used per run. The runs consisted of a 41-cm field of view (FOV) (AP), $41 \mathrm{~cm}$ FOV (lateral and oblique), frame rate $40 \mathrm{f} / \mathrm{s}$, and a $1024 \times$ 1024 matrix. The spatial resolution was $0.32 \times$ $0.32 \mathrm{~mm}$. Additionally, this DSA protocol included rotational spin angiograms with 3D reconstructions. Images were acquired with a floor mounted L-Arm and offset C-arm at a rotational speed of $50 \mathrm{f} / \mathrm{s}$ covering +/- 95 degree. A volume of 18 $\mathrm{mL}$ of nonionic contrast medium was injected by use of an injector with a velocity of $4 \mathrm{~mL} / \mathrm{s}$. While the catheter was within each of the three major arteries standard AP, lateral, and oblique DSA runs were obtained. A single rotational 3D rotational angiography acquisition was typically obtained before removing the catheter from each vessel. All injections were done using $100 \%$ contrast concentration. Image acquisition was started $1-4$ seconds after contrast material injection, followed by a 4-mL/s injection for a total of 18 
$\mathrm{mL}$. The tube rotation arc was $160^{\circ}$ (only 1 rotation used) with a rotation time of approximately 40 degrees per second. These were reconstructed in a $256 \times 256$ matrix. Three-dimensional rotational angiography was performed in each patient who underwent conventional DSA unless there was clinical necessity based on patient instability and emergent need to treat, such as ventriculostomy manipulation or deteriorating mental status.

\section{Image interpretation}

An intervention radiologist with more than 20 years of experience assessed the conventional DSA images and reconstructions of 3D-DSA performed for each of the 50 patients. The following factors were individually assessed in each reconstruction: the presence of an aneurysm, detection of aneurysm neck, location and size of the aneurysm. The overall quality of conventional DSA and 3D reconstruction images was rated on a four-point scale, as follows: 1 - insufficient; 2 sufficient; 3 - good; and 4 - excellent. Detection of aneurysm neck is designated using (+) for visible and (-) for not visible. The size of aneurysms was measured in millimeters $(\mathrm{mm})$. The source, unsubtracted images were also reviewed regard to the possibility of artifacts in patients with significant metal present or patient motion. After determining consensus in each case as to the presence of an aneurysm, a reviewer measured each aneurysm's maximum size on 3D rotational angiography in a similar projection as that measured on the conventional to obtain a correlation of the maximum size between modalities. The largest diameter of each aneurysm was measured in millimeters to one decimal places and graded as large ( $\geq 10 \mathrm{~mm})$, medium $(3-9 \mathrm{~mm})$, or small ( $<3 \mathrm{~mm})$, in a fashion similar to the conventional DSA measurements.

Detection of aneurysm neck was valued on $0-6$ scale: 0 - aneurysm and aneurysm neck was not detected; 1 - detection of suspected aneurysm neck; 2 - detection of aneurysm without her neck; 3 - detection of one aneurysm and her neck; 4 - detection of two aneurysms with one aneurysm neck; 5 - detection of two aneurysms with their necks; 6 - detection of three aneurysm with their necks.

Determination of size of aneurysms was valued on 0 - 6 scale: 0 - aneurysm not detected; 1 - detected small ( $<3 \mathrm{~mm}$ ) aneurysm; 2 - detection of three small aneurysms; 3 - detection of one middle $(3-9 \mathrm{~mm})$ and one small aneurysm; $4-$ detection of one middle aneurysm; 5 - detection of one middle and one large ( $\geq 10 \mathrm{~mm})$ aneurysm; 6 - detection of one large aneurysm.

\section{Statistical analysis}

The analysis was performed in the statistical software SPSS Statistics for Windows, version 25.0 (SPSS Inc., Chicago, IL, USA). The hypothesis of the paper are tested by using quantitative methods. The analysis used graphical and tabular presentation methods, descriptive statistics methods, namely the median as the middle value, and the interquartile range as an indicator of the dispersion of values around the mean value. The normality of the distribution was examined by the Kolmogorov-Smirnov test. Due to the nonlinear distribution of data, correlation testing was performed with Spearman correlation (rho), while differences in values were tested with the Mann-Whitney $U$ test (Z).

The correlation between non-numeric categorical values was tested by the Chi-square test. Statistical significance was set with a $P$ value of less than 0.05 .

\section{RESULTS}

A total number of 60 aneurysms were detected in 50 patients. In five patients, neither conventional DSA or 3D technique revealed an intracranial aneurysm. Three-dimensional technique confirmed

Table 1. Correlation between the degree of aneurysm neck determined by 3D reconstructions and DSA.

\begin{tabular}{|l|c|c|c|}
\hline \multicolumn{1}{l|}{} & $\mathbf{N}$ & rho & \multicolumn{1}{c|}{$\boldsymbol{P}$} \\
\hline Detection of aneurysm neck - 3D \& DSA & 50 & 0.068 & 0.637 \\
\hline *Spearmans correlation & & & \\
\hline
\end{tabular}


54 aneurysms while conventional DSA detected 38 aneurysms. Detected aneurysms were located in anterior cerebral artery (ACA, $n=19)$, communicant artery anterior ( $C A A, n=22)$, middle cerebral artery (MCA, $n=22)$, basilar artery $(B A, n=10)$, communicant artery posterior ( $C A P, n=8)$, and posterior cerebral artery (PCA, $n=2$ ) circulation.

\section{Detection of aneurysm neck}

Three-dimensional technique detected 52 aneurysmal necks while conventional DSA detected 24 aneurysm necks in 50 patients. Three dimensional technique detected aneurysm neck in 38 patients while conventional DSA detected aneurysm neck in 24 patients. Difference between conventional DSA and 3D reconstructions in detection of intracranial aneurysmal neck in number of patients is not statistically significant $(\chi 2=2.683 ; \quad d f=1$; $P=0.101)$. Chi square test did not confirm an association between the two methods in detection of aneurysm neck, but there was a difference in detection performance between $3 \mathrm{D}$ reconstruction and conventional DSA ( $\chi 2=0.025 ; P=0.874)$.

In 26 patients where conventional DSA failed to detect aneurysm neck, 3D technique detected aneurysm neck 20 times. In 12 patients where 3D

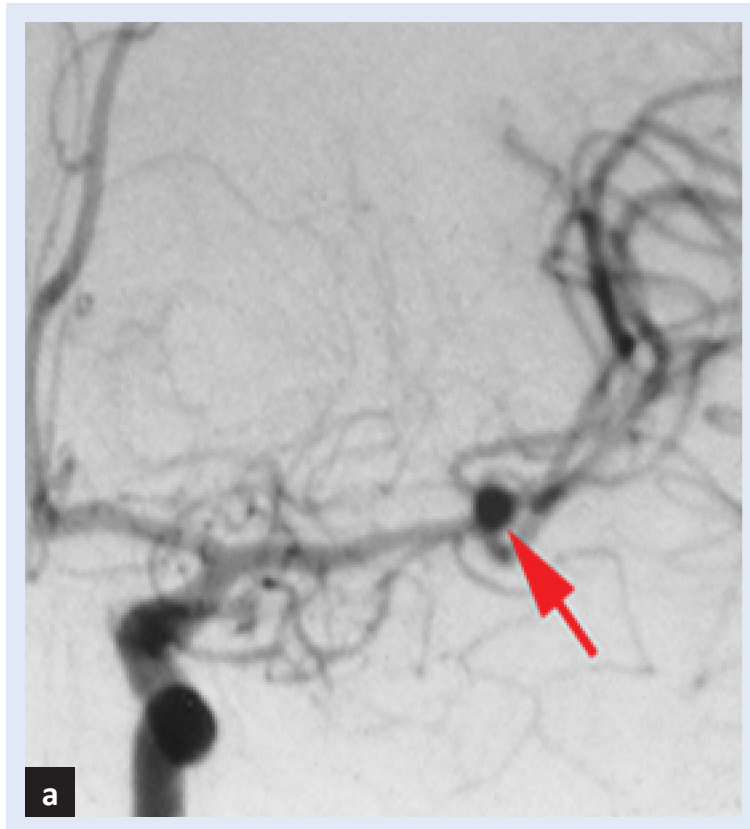

technology failed to detect aneurysm neck, conventional DSA detected aneurysm neck six times. In nine patients, conventional DSA detected aneurysm without neck visualization, while 3D technique detected an aneurysm with visualization of neck. Overall, 3D reconstructions detected 31 additional aneurysm neck compared with conventional DSA. Conventional DSA detected six additional aneurysm necks. Sensitivity of 3D reconstruction was $75 \%$, respectively, in $75 \%$ of cases when DSA reconstruction determines the existence of aneurysm neck, 3D reconstruction will determine the same. Specificity of the test was $23.08 \%$, respectively, $23.08 \%$ of patients in whom 3D reconstruction did not determine the existence of the aneurysm neck in the total number of patients whose DSA reconstruction did not determine the existence of the aneurysm neck. An empirical rho value of $0.068(P=0.637)$ indicates that there is no statistically significant correlation between the degree of aneurysm neck determined by the use of two different methods (Table 1). Figure 1 shows an example where conventional DSA failed to detect an aneurysmal neck, while in the same patient 3D reconstruction successfully detected an aneurysmal neck.

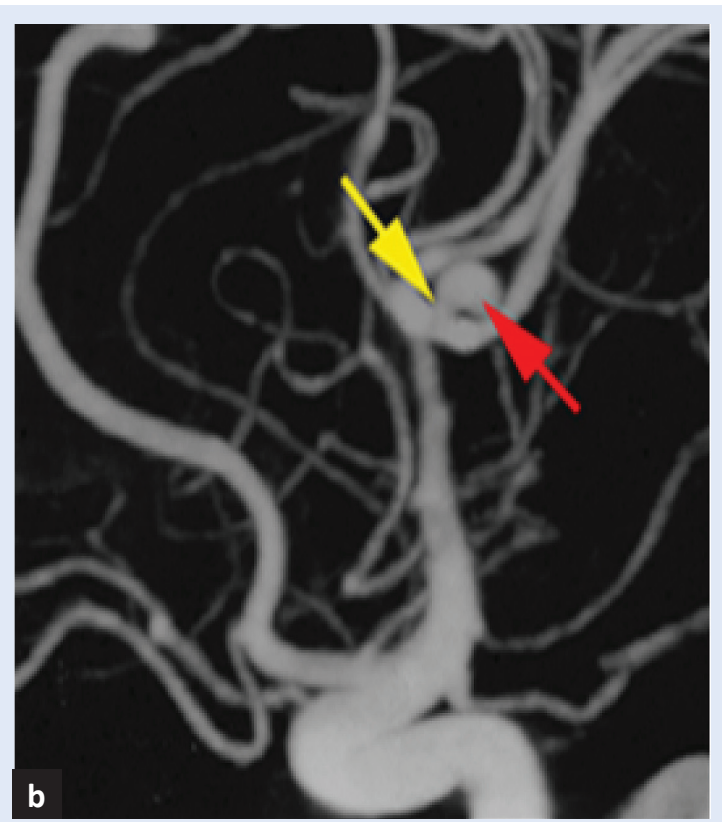

Figure 1. A case with detected aneurysm on the left middle cerebral artery. Conventional DSA detected intracranial aneurysm without visualization of aneurysmal neck (red arrow) (1a). Maximum intensity projection 3D reconstruction method detected an intracranial aneurysm (red arrow) with clear visualization of aneurysmal neck (yellow arrow) (1b). 


\section{Detection of small aneurysms}

The mean size of all aneurysms on 3D reconstructions was $3.52 \pm 3.47$. The mean size of all aneurysms on conventional DSA was $3.50 \pm 3.30$. The maximum diameter of all aneurysms was $1-10$ $\mathrm{mm}$. A total of 23 small aneurysms ( $<3 \mathrm{~mm}$ ) were detected by $3 D$ reconstructions. Seven small aneurysms were detected by conventional DSA. In 14 patients small aneurysms were detected by $3 D$ reconstructions, while in the same patients conventional DSA failed to detect a small aneurysms. The 13 aneurysms out of the total number of detected aneurysms were larger on the 3D reconstructions compared with conventional DSA. Five aneurysms were $5 \mathrm{~mm}$ larger than the same aneurysms shown by conventional DSA, while seven aneurysms were 1-3 $\mathrm{mm}$ larger on the 3D reconstructions. Six aneurysms were larger on the conventional DSA compared with 3D reconstructions. The difference in size of these aneurysms in comparison with the size measured at 3D reconstruction is at most $2 \mathrm{~mm}$.

Our results show that 3D technique and conventional DSA do not show the same degree (0-6) of aneurysm size (Figure 2).

Testing with Spearmans rank correlation revealed a statistically significant and positive relationship between the detected size of the aneurysm using
3D reconstruction technology and DSA technology. Therefore, if the use of one technology detects a larger size of the aneurysm, a larger aneurysm will also be detected using another technology ( $r$ o $=0.389 ; P<0.01$ ).

The mean value of aneurysm neck detection rate was 3 points higher in patients who had a visible aneurysm neck by 3D reconstruction, and the test found a difference $(Z=5.28 ; P<0.001)$. The mean value of the aneurysm size was 4 points higher in patients who had a visible aneurysm neck by $3 D$ technique, and testing revealed a difference $(Z=5.42 ; P<0.001)$. Thus, with 3D technique, there was a difference in determining the size of the aneurysm in which the neck is visible relative to aneurysms without a detected neck.

Also, in the case of conventional DSA, this test found the same difference (Table 2). That is, the mean value of the degree of neck aneurysm detection was 3 points higher in patients who had a visible neck aneurysm, and the test revealed the difference $(Z=5.70 ; P<0.001)$. The mean value of the size of the aneurysm was 4 points higher in patients who had a visible neck of the aneurysm, and testing revealed a difference $(Z=3.91 ; P<0.001)$. The size of the aneurysm affects the aneurysm neck detection by conventional DSA.

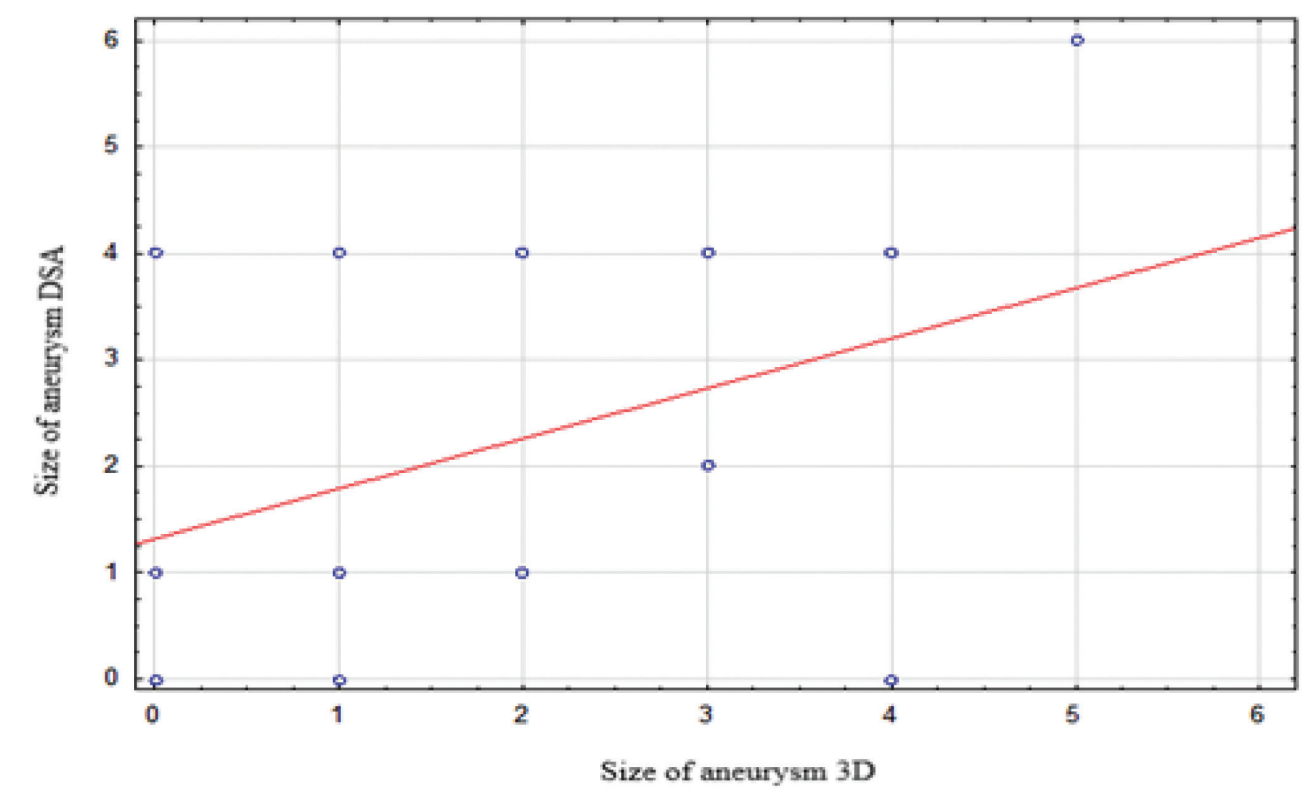

Figure 2. Degrees of aneurysm size by DSA and 3D reconstructions. 
Table 2. Differences in the values obtained by conventional DSA.

\begin{tabular}{|c|c|c|c|c|c|c|c|c|}
\hline & \multirow{2}{*}{$\begin{array}{c}\text { Detection of } \\
\text { aneurysm neck }\end{array}$} & \multirow[b]{2}{*}{$\mathbf{N}$} & \multirow{2}{*}{$\begin{array}{l}\text { Mean } \\
\text { Rank }\end{array}$} & \multicolumn{3}{|c|}{ Percentiles } & \multirow[b]{2}{*}{ z } & \multirow[b]{2}{*}{$P$} \\
\hline & & & & 25th & $\begin{array}{c}\text { 50th } \\
\text { (Median) }\end{array}$ & 75th & & \\
\hline \multirow{3}{*}{$\begin{array}{l}\text { Aneurysm size } \\
\text { (degrees 0-6) }\end{array}$} & No & 26 & 18.50 & & & & \multirow{3}{*}{-3.91} & \multirow{3}{*}{$<0.001$} \\
\hline & Yes & 24 & 33.08 & .00 & 4.00 & 4.00 & & \\
\hline & Total & 50 & & & & & & \\
\hline \multirow{3}{*}{$\begin{array}{l}\text { Detection of aneurysm neck } \\
\text { (degrees } 0-6 \text { ) }\end{array}$} & No & 26 & 15.04 & & & & \multirow{3}{*}{-5.70} & \multirow{3}{*}{$<0.001$} \\
\hline & Yes & 24 & 36.83 & .00 & 2.00 & 3.00 & & \\
\hline & Total & 50 & & & & & & \\
\hline
\end{tabular}

*Mann-Whitney U test

\section{Additional aneurysms - 3D reconstructions}

After interpretation of acquired images, there were 24 additional aneurysms with necks detected by $3 \mathrm{D}$ reconstructions. The mean size of additional aneurysms was $3.98 \pm 3.29$ (range $1-6.4$ $\mathrm{mm}$ ). Of detected additional aneurysms with 3D reconstruction, 13 were less than $3 \mathrm{~mm}$ in maximum diameter. Additional aneurysms detected with $3 D$ reconstruction were located in $A C A$ $(n=9), \operatorname{MCA}(n=8), \operatorname{CAP}(n=5)$ and PCA $(n=2)$ circulation.

No additional aneurysms were found in $B A$ or CAA circulation with $3 D$ reconstruction. In three patients, four aneurysms that was suspected on conventional DSA were clearly classified as an ad-
Three-dimensional technique has proven to be a more successful in detecting additional aneurysms, but there is no statistical difference. Conventional DSA still represent a useful tool in the evaluation of aneurysm morphology, but when combine with 3D technique detection rates are improved.

ditional multiple aneurysms on the basis of 3D reconstruction. Eleven patients with more than one aneurysms were confirmed by 3D reconstruction, while in the same patients conventional DSA confirmed one aneurysm or failed to revealed an intracranial aneurysm (Figure 3).
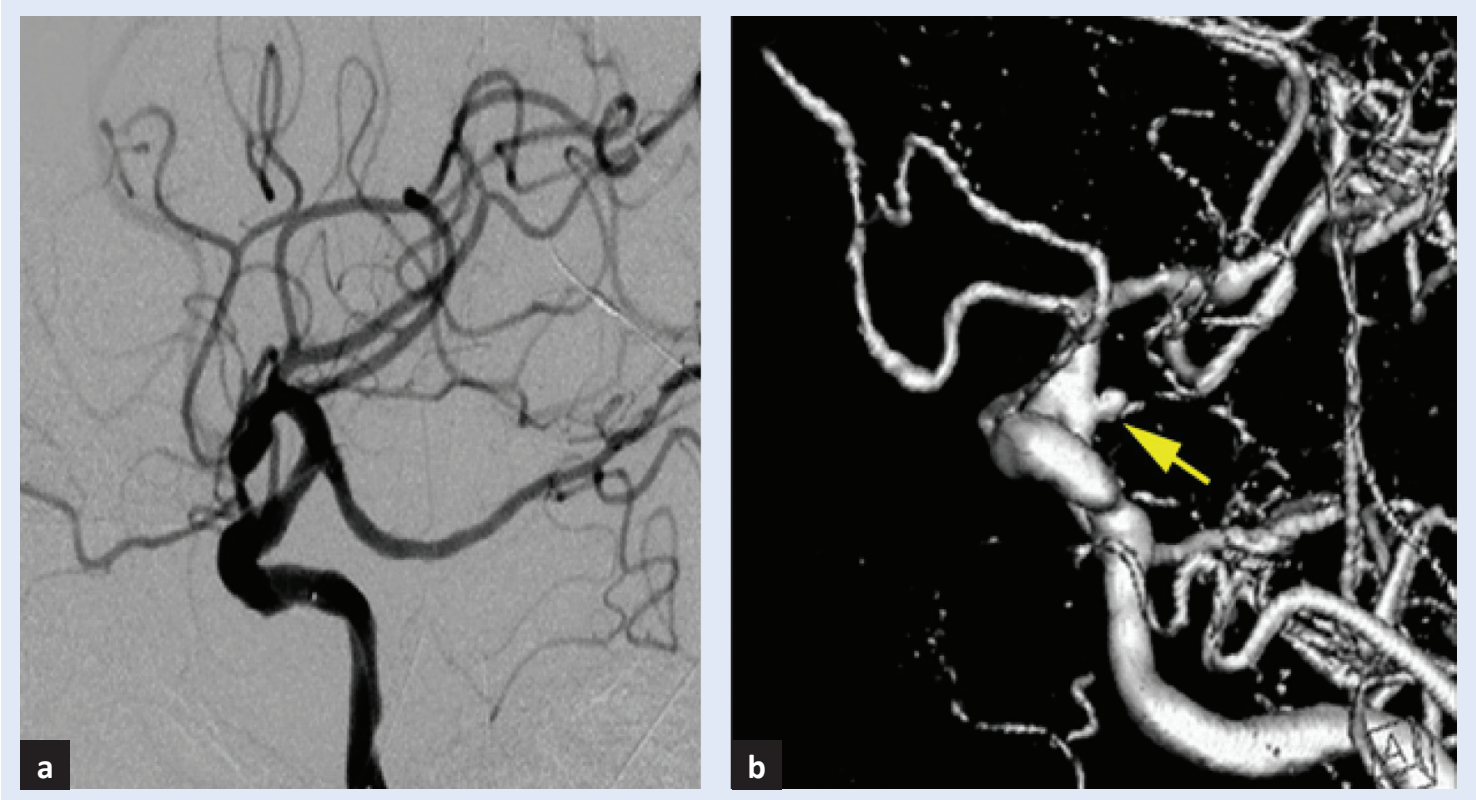

Figure 3. A case of detected intracranial aneurysm on the left posterior communicant artery. Conventional DSA failed to detect an aneurysm (3a). Three-dimensional reconstructed surface shaded display image with detected an intracranial aneurysm and the neck of an aneurysm (3b). 


\section{Additional aneurysms - digital subtraction angiography}

Digital subtraction angiography detected six additional intracranial aneurysms. The mean size of these additional aneurysms was $2.66 \pm 2.16$. Two of these additional aneurysms were small size $(<3 \mathrm{~mm})$. Rest of them were $\geq 3 \mathrm{~mm}$. These additional were located in CAP $(n=1), C A A(n=1), M C A$ $(n=1), B A(n=2), C A P(1)$ circulation. No additional aneurysms were found by conventional DSA in ACA or PCA circulation. Of the five suspected aneurysms on conventional DSA, three aneurysms located in CAP circulation. Other two was in CAP, and in BA circulation. A false negative detection rate of $14.39 \%$ (24 of 60 aneurysms) for conventional DSA was noted.

\section{DISCUSSION}

Conventional DSA is still the gold standard method in many centers for preoperative intracranial aneurysms detection ${ }^{10}$. With the development of computed software, 3D rotational DSA become infallible clinical tool in evaluation of intracranial aneurysms and their morphology, especially after clipping. Three-dimensional DSA combines the anatomic resolution of DSA with 3D visualization abilities. Compared with the conventional DSA, the 3D-DSA modality has more information that can easily identify aneurysms, providing multiple viewing angles with the 3D techniques such as multiplanar reconstruction, maximum intensity projection, shaded surface display and volume rendering. Some authors stated that 3D-DSA with $3 \mathrm{D}$ reconstructions is the golden standard in evaluating of intracranial aneurysms ${ }^{11-13}$. Microsurgical clipping of aneurysms require exact spatial understanding of aneurysm morphology ${ }^{14}$. Threedimensional volumetric reconstructions of 3DDSA are a valuable tool for intracranial vessels imaging. They play a crucial role in the evaluation of intracranial aneurysms, especially in evaluation of the aneurysm neck and the aneurysm recanalization. Three-dimensional reconstructions are valuable tool in the evaluation of cerebral vessels, especially in the detection of small intracranial aneurysms ${ }^{15}$. The results of our study confirm the stated theses. Three-dimensional reconstructions detected more intracranial aneurysm necks compared with conventional DSA. In our study $3 \mathrm{D}$ reconstructions also detected more small intracranial aneurysms compared with conventional DSA. Wong et al. also state that aneurysm neck was recognized significantly better on 3D reconstruction technology than on conventional DSA. Their results show that 3D reconstruction technology detected more aneurysm necks compared with conventional DSA ${ }^{16}$. In our study there is no statistical significantly difference between conventional DSA and 3D reconstructions in detection of aneurysm neck in number of patients, but there was a difference in detection performance between $3 \mathrm{D}$ reconstruction and conventional DSA. Respectively, 3D reconstruction technology detected more necks of intracranial aneurysms than conventional DSA. Therefore, the results of our study are consistent with Wong's results in detection of the necks of aneurysms. Studies reported so far that 3D reconstruction technique is more sensitive in detecting small aneurysms than the conventional DSA, despite its lower spatial resolution ${ }^{17,18}$. The results of our study are consistent with previous results with regard to the presentation of small aneurysms. The results of our study shows that 3D reconstruction technology turned out to be more successful in the detection of small aneurysms compared with conventional DSA.

The results of a study conducted by Wong et al shows that there was no significant difference in aneurysm size between 3D and 2D-DSA. The sizes of aneurysm necks were found to be significantly larger in 3D reconstructions than on 2D-DSA ${ }^{17}$. Our results showing a positive relationship between the detected size of the aneurysm using $3 \mathrm{D}$ reconstruction technology and conventional DSA, that is, if the use of one technology detects a larger size of the aneurysm, a larger aneurysm will also be detected using another technology. In a few patients the size of aneurysms found to be larger on 3D reconstruction techniques than on conventional DSA. Results of a study conducted by Schneider et al shows that in 8 of 20 evaluated cases they observed aneurysm neck overestimation in 3D rotational angiography-derived vascular models compared with conventional $\mathrm{DSA}^{19}$. Some authors stated that 3D reconstructi- 
ons tend to overestimate the area filled with the contrast agent. Therefore, the actual neck size may be smaller than the one measured on 3D reconstruction and conventional DSA images ${ }^{20}$. In regards to the studies cited, more attention should be paid to the overestimation of the neck of an aneurysm. The size of the neck of an aneurysm was not measured in our study, which represents one of the limitations of this study.

The results of a study conducted by Van Rooj et al. shows that $3 \mathrm{D}$ reconstructions depicts considerably more small (<or=3 $\mathrm{mm}$ ) additional aneurysms than DSA. Shi et al state that 3D reconstruction techniques, especially VR images, not only clearly reveals aneurysms and aneurysmal morphology, but also detects additional aneurysms missed by conventional DSA, especially small aneurysms less than $3 \mathrm{~mm}^{21}$. Results of our study are consistent with Van Rooj's and Shi's results. In our study, 3D reconstruction technology detected more small additional aneurysms than conventional DSA. Compared to the studies conducted by Van Rooj et al and Shi et al., a smaller number of patients were used in our study. However, most studies have a less number of patients compared to the sample size of our study $^{19,21,22}$. In the studies cited above there was mostly two or three readers of images, while in our study there was only one interpreter of conventional DSA and 3D reconstructed images. This fact represents a major limitation of our study. However, the interpreter was blinded to all previous data obtained while conducting the measurements. An additional limitation of our study is that the default threshold values on the equipment used in this study may not be equal to those on other types of equipment. Biplane devices are the most commonly used in previous studies, while in our study single plane angiography unit was used ${ }^{8,10,11,15,21}$. In Bosnia and Herzegovina was also conducted similar researches, but without comparison of DSA and 3D technique in size and neck evaluation of intracranial aneurysms. This research was focused on presence and location of intracranial aneurysms. Franjić and Mašković stated that 3D technique is better in the detection of intracranial aneurysms and their location, but difference was not statistically signifi- cant $^{23}$. With the development of technology in developed countries research on advanced devices and techniques has been conducted, such as research conducted by Lang et al which was based on comparison between four-dimensional (4D) and 3D-DSA in the evaluation of intracranial aneurysms ${ }^{24}$. In recent years, magnetic resonance angiography and computed tomography angiography are methods of first choice in the evaluation of postoperative intracranial aneurysm, while DSA remains golden standard method in the evaluation of preoperative intracranial aneurysms ${ }^{25}$. The results of our study confirm the thesis of the aforementioned research.

\section{CONCLUSIONS}

Three-dimensional reconstructions are more successful in the detection of aneurysms, their necks and small aneurysms in comparison to conventional DSA, but difference is not statistically significant. There was found statistically significant and positive relationship between the detected size of the aneurysm using 3D reconstruction technology and conventional DSA technology. The size of the aneurysm statistically significant affects the aneurysm neck detection by conventional DSA. Three-dimensional technique proved to be better in the detection of additional intracranial aneurysms when compared to conventional DSA, but difference is not statistically significant. Digital subtraction angiography still represent a useful tool in the evaluation of aneurysm necks and in the evaluation of aneurysm size, but when combine with 3D reconstruction technologies detection rates of aneurysm necks and small aneurysms are improved.

Conflicts of interest: The authors declare that there is no conflict of interest.

\section{LITERATURE}

1. Vlak MH, Algra A, Brandenburg R, Rinkel GJ. Prevalence of unruptured intracranial aneurysms, with emphasis on sex, age, comorbidity, country, and time period: a systematic review and meta-analysis. Lancet Neurol 2011;10:626-636.

2. Suarez JI, Tarr RW, Selman WR. Aneurysmal subarachnoid hemorrhage. N Engl J Med 2006;354:387-396.

3. Rajabzadeh-Oghaz $H$, Varble $N$, Shallwani $H$, Tutino VM, Mowla A, Shakir HJ et al. Computer-assisted three-dimensional morphology evaluation of intracranial aneu- 
rysms. World Neurosurg [Internet]. 2018;119. [cited 2021 Jun 22]. Available from: https://www.ncbi.nlm.nih. gov/pmc/articles/PMC6383522/.

4. Wiśniewski K, Tomasik B, Bobeff EJ, Stefańczyk L, Hupało $M$, Jaskólski DJ. Predictors for ophthalmic segment aneurysms recanalization after coiling and flow diverter embolization in 6- and 12-month follow-up. J Clin Neurosci 2019;68:151-157.

5. Toyooka T, Wada K, Otani N, Tomiyama A, Takeuchi S, Tomura $\mathrm{S}$ et al. Potential risks and limited indications of the supraorbital keyhole approach for clipping internal carotid artery aneurysms. World Neurosurg X [Internet]. 2019;2. [cited 2021 Jun 21]. Available from: https:// www.ncbi.nlm.nih.gov/pmc/articles/PMC6580886.

6. Kaufmann TJ, Kallmes DF. Diagnostic cerebral angiography: archaic and complication-prone or here to stay for another 80 years? Am J Roentgenol 2008;190:1435-1437.

7. Okahara M, Kiyosue $\mathrm{H}$, Yamashita $\mathrm{M}$, Nagatomi $\mathrm{H}$, Hata $\mathrm{H}$, Saginoya T et al. Diagnostic accuracy of magnetic resonance angiography for cerebral aneurysms in correlation with 3D digital subtraction angiography images: a study of 133 aneurysms. Stroke 2002;33:1803-1808.

8. Anxionnat R, Bracard S, Ducrocq X, Kerrien E, Braun M, Vaillant $R$ et al. Intracranial aneurysms: clinical value of 3D digital subtraction angiography in the therapeutic decision and endovascular treatment. Radiology 2001; 218:799-808.

9. Abboud T, Rustom J, Bester M, Czorlich P, Vittorazzi E, Pinnschmidt $\mathrm{HO}$ et al. Morphology of ruptured and unruptured intracranial aneurysms. World Neurosurg 2017;99:607-610.

10. Hochmuth A, Spetzger U, Schumacher M. Comparison of three-dimensional rotational angiography with digital subtraction angiography in the assessment of ruptured cerebral aneurysms. Am J Neuroradiol [Internet]. 2002;23. [cited 2021 Jun 21]. Available from: https:// www.ncbi.nlm.nih.gov/pmc/articles/PMC8185715/.

11. Van Rooij WJ, Sprengers ME, de Gast AN. 3D rotational angiography: the new old standard in the detection of additional intracranial aneurysms. Am J Neuroradiol [Internet]. 2008;29. [cited 2021 Jun 21]. Available from: https://www.ncbi.nlm.nih.gov/pmc/articles/ PMC8128578/.

12. Marbacher S, Kienzler JC, Mendelowitsch I, D'Alonzo D, Andereggen $\mathrm{L}$, Diepers $\mathrm{M}$ et al. Comparison of intra- and postoperative 3-dimensional digital subtraction angiography in evaluation of the surgical result after intracranial aneurysm treatment. Neurosurgery 2019:487: 689-696.

13. Goertz L, Kabbasch C, Borggrefe J, Hamisch C, Telentschak $\mathrm{S}$, von Spreckelsen $\mathrm{N}$ et al. Preoperative three-dimensional angiography may reduce ischemic complications during clipping of ruptured intracranial aneurysms. World Neurosurg [Internet]. 2018;120. [cited 2021 Jun 21]. Available from: https://pubmed.ncbi. nlm.nih.gov/30218797/.

14. Cieściński J, Serafin Z, Strześniewski P, Lasek W, Beuth W. DSA volumetric 3D reconstructions of intracranial aneurysms: A pictorial essay. Pol J Radiol [Internet]. 2012;77. [cited 2021 Jun 21]. Available from: https://www.ncbi. nlm.nih.gov/pmc/articles/PMC3403801/.
15. Wong SC, Nawawi O, Ramli N, Abd Kadir KA. Benefits of 3 D rotational DSA compared with 2D DSA in the evaluation of intracranial aneurysm. Acad Radiol [Internet]. 2012;19. [cited 2021 Jun 21]. Available from: https:// pubmed.ncbi.nlm.nih.gov/22578227/.

16. Zhou B, Li MH, Wang W. Three-dimensional volume-rendering technique in the angiographic follow-up of intracranial aneurysms embolized with coils. J Neurosurg 2010;112:674-680.

17. Ishihara $\mathrm{H}$, Kato $\mathrm{S}$, Akimura T. Angiogram-negative subarachnoid hemorrhage in the era of three-dimensional rotational angiography. J Clin Neurosci [Internet]. 2007;14. [cited 2021 Jun 21]. Available from: https:// pubmed.ncbi.nlm.nih.gov/17258133/.

18. Kiyosue $\mathrm{H}$, Okahara $\mathrm{M}$, Tanoue $\mathrm{S}$. Detection of the residual lumen of intracranial aneurysms immediately after coil embolization by three-dimensional digital subtraction angiographic virtual endoscopic imaging. Neurosurgery 2002;50:476-485.

19. Schneiders JJ, Marquering HA, Antiga L, van den Berg R, VanBavel E, Majoie CB. Intracranial aneurysm neck size overestimation with $3 \mathrm{D}$ rotational angiography: the impact on intra-aneurysmal hemodynamics simulated with computational fluid dynamics. Am J Neuroradiol [Internet]. 2013;34. [cited 2021 Jun 21]. Available from: https://www.ncbi.nlm.nih.gov/pmc/articles/ PMC7966331/.

20. Balaji A, Rajagopal N, Yamada Y, Teranishi T, Kawase T, Kato $Y$. A retrospective study in microsurgical procedures of large and giant intracranial aneurysms: an outcome analysis. World Neurosurg X [Internet]. 2019;2. [cited 2021 Jun 21]. Available from: https://www.ncbi.nlm.nih. gov/pmc/articles/PMC6580892/.

21. Shi WY, Li YD, Li MH, Gu BX, Chen SW, Wang W et al. 3D rotational angiography with volume rendering: the utility in the detection of intracranial aneurysms. Neurol India [Internet]. 2010;58. [cited 2021 Jun 21]. Available from: https://www.neurologyindia.com.

22. Kumar S, Gaikwad SB, Mishra NK. 3D Rotational Angiography in follow-up of clipped intracranial aneurysms. ISRN Radiol [Internet]. 2014;935280. [cited 2021 Jun 21]. Available from: https://www.ncbi.nlm.nih.gov/pmc/ articles/PMC4045552/.

23. Franjić $D$, Mašković J. Comparison of conventional DSA and $3 D$ technique in the detection of intracranial aneurysms and their location. Health Bulletin [Internet]. 2018;1. [cited 2020 November 14]. Available from: https://fzs.sum.ba/sites/default/files/Glasnik\%207.pdf.

24. Lang $S$, Hoelter $P$, Birkhold Al, Schmidt M, Endres J. Quantitative and qualitative comparison of 4D-DSA with 3D-DSA using computational fluid dynamics simulations in cerebral aneurysms. AJNR Am J Neuroradiol [Internet]. 2019;40. [cited 2021 Jun 21]. Available from: https://www.ncbi.nlm.nih.gov/pmc/articles/ PMC7048460/.

25. Howard BM, Hu R, Barrow JW, Barrow DL. Comprehensive review of imaging of intracranial aneurysms and angiographically negative subarachnoid hemorrhage. Neurosurg Focus [Internet]. 2019;47. [cited 2021 Jun 21]. Available from: https://pubmed.ncbi.nlm.nih. gov/31786554/. 